\title{
Dossier México y Centroamérica
}

\section{Presentación}

Esta presentación no pretende ser un análisis sobre la inmensa historiografía existente de las relaciones que guardan México y Centroamérica desde épocas remotas. Más bien busca ser una reflexión de los múltiples vínculos que mantiene México con la región centroamericana, la cual tuvo periodos de conflictos y alianzas, pero aun con estos altibajos, los trabajos presentados evidencian que se mantuvo y mantiene una estrecha relación en el terreno de lo político, lo social, lo económico y, desde luego, lo cultural. En suma es una aportación interdisciplinaria desde la Ciencias Sociales que pretende abonar a la interacción histórica que mantiene México con los países del istmo.

Me gustaría iniciar explicando el por qué y el cómo surgió la idea de realizar este número temático. En el año del 2018 fui invitada por las profesoras Macarena Barahona y Carolina Mora, de Estudios Generales de la Universidad de Costa Rica para impartir una conferencia sobre la Guerra Civil de 1948 en Costa Rica, en ese espacio expuse tan solo una pequeña parte de cómo México se vinculó a ese acontecimiento, desde el prisma del exilio político. Cabe mencionar que el territorio mexicano albergó a varias personalidades de diferentes tendencias políticas, entre ellos José Figueres y su hermano, posteriormente llegaron Rafael Calderón Guardia y los comunistas, entre quienes encontramos a Manuel Mora Valverde y la célebre poeta María Isabel Carbajal, conocida como Carmen Lyra, quien falleció en el territorio mexicano el 13 de mayo de 1949, es por eso que este año se conmemora 70 años de su muerte. En el contexto de la presentación de la conferencia se presentó la exposición Conmemoración de los 70 años de la Guerra Civil de 1948 exilio, guerra y memoria en la Biblioteca Nacional de Costa Rica, ahí se evidenció como varios periódicos de diferentes países del continente retrataron este conflicto en sus principales páginas.

\section{(c) (i) (2)}

La Revista Estudios es editada por la Universidad de Costa Rica y se distribuye bajo una Licencia Creative Commons Atribución-NoComercial-CompartirIgual 3.0 Costa Rica. Para más información envíe un mensaje a 
En este momento siendo Directora General del Acervo Histórico Diplomático de la Secretaría de Relaciones Exteriores y coordinadora académica del Proyecto PAPIIT "Exilios españoles desde Latinoamérica. Nuevas perspectivas históricas y de investigación" (clave IA301819) de la UNAM, propuse a Carolina Mora Chichilla, directora de la prestigiada Revista Estudios de la UCR realizar este número con investigadores pertenecientes al Proyecto PAPIIT que se dedican a estudiar desde diferentes enfoques, periodos y temas las relaciones de México con Centroamérica. Además se cuenta con la participación de un investigador de la Universidad Iberoamericana y la hoy Encargada del despacho del Instituto Matías Romero, academia diplomática mexicana. De tal manera que lo que hoy el lector tiene en sus manos son miradas mexicanas sobre diferentes hechos históricos que sucedieron en Guatemala, Costa Rica, El Salvador y en dos casos, que mediante el exilio político se puede ver la presencia de países como Nicaragua, Honduras y España. Lo que es necesario destacar es que estos investigadores mexicanos mantienen un diálogo con sus pares centroamericanos mediante el uso de varias obras, que están referenciadas en los artículos. Además de que incorporan fuentes primarias.

Para la organización de este Dossier, privilegié un orden cronológico, ya que estos artículos rescatan el pasado de estas relaciones que hoy día permiten mostrar el por qué nuestros países mantienen un vínculo en el presente. Así ubicamos en primer término el trabajo de Agustín Sánchez Andrés, denominado Vecinos en conflicto: los diferendos territoriales de México con Centroamérica y Guatemala, 1823-1897, quien destaca los problemas derivados del proceso de fragmentación de la América española a raíz de la independencia que afectaron las relaciones de México con Centroamérica y posteriormente con Guatemala. La anexión de Chiapas y del Soconusco a la República Mexicana y los posteriores desacuerdos en el trazado de la frontera, tras la independencia de Guatemala de la Federación Centroamericana en 1839, conflictuaron las relaciones bilaterales hasta la firma del Tratado Herrera-Mariscal en 1882. Este

\section{(c) (i) (2)}

La Revista Estudios es editada por la Universidad de Costa Rica y se distribuye bajo una Licencia Creative Commons Atribución-NoComercial-CompartirIgual 3.0 Costa Rica. Para más información envíe un mensaje a 
trabajo muestra la dificultad de dos territorios vecinos que al adquirir independencia tuvieron que resolver sus límites fronterizos para configurar los nuevos territorios, como fue el caso de Guatemala y México en el siglo XIX.

El segundo trabajo es de la autoría de Joaquín Lozano Trejo, el cual tituló Gonzalo Robles y la Oficina de Investigaciones Industriales del Banco de México. Un costarricense en el impulso a la industrialización mexicana, 19421952. El autor señala que Robles fue de origen costarricense, y llegó a México a principios del siglo XX en donde realizó sus estudios superiores en la Escuela Nacional de Agricultura, precisamente durante el estallido de la Revolución Mexicana. Lozano Trejo analiza la labor del personaje en el establecimiento de la Oficina de Investigaciones Industriales, cuyo objetivo fue contribuir al proyecto de industrialización que se impulsó en el país. Sobre este tema cabe señalar que hoy día poco se conoce de la presencia de centroamericanos trabajando en la Administración Pública mexicana en los primeros años del siglo XX. Hoy una figura que se ha rescatado y que comparte ese tiempo con Gonzalo Robles es el poeta, político y periodista Rogelio Fernández Güell, quien llegó a México a finales del siglo XIX y tuvo un papel relevante durante el breve gobierno del presidente mexicano Francisco I. Madero.

Por ejemplo, Fernández Güell, como tantos centroamericanos llegaron a México perseguidos por los gobiernos autoritarios en turno a lo largo de todo el siglo XX y en algunos casos lograron organizarse para tratar de incidir en el fin de esos gobiernos y solidarizarse con exiliados de otras latitudes, ese fue el caso de la Unión Democrática Centroamericana (UDC). Sobre ese tema José Francisco Mejía Flores presenta su escrito titulado La Unión Democrática Centroamericana en México y su solidaridad con los republicanos españoles, 1943-1945. El autor explica que las actividades de esta organización se enmarcaron en la coyuntura del desarrollo de la Segunda Guerra Mundial, justo en el momento de la proyección de un probable triunfo aliado sobre el nazi fascismo. En ese sentido analiza la solidaridad que esta organización

\section{(c) (i) (9) (2)}

La Revista Estudios es editada por la Universidad de Costa Rica y se distribuye bajo una Licencia Creative Commons Atribución-NoComercial-CompartirIgual 3.0 Costa Rica. Para más información envíe un mensaje a 
centroamericana manifestó a la causa de la República Española en su lucha anti franquista hasta 1945 y el destacado papel que tuvo el escritor costarricense Vicente Sáenz, quien realizó actividades periodísticas en la península ibérica durante la guerra civil y se convirtió en un amplio especialista de los asuntos españoles y gran amigo de la República española. Su afinidad con el proyecto de Juan Negrín es manifiesta en la correspondencia que sostiene con el líder sindical de la española Unión General de Trabajadores (UGT), Amaro del Rosal Díaz.

El trabajo de quien suscribe esta presentación y que lleva por título Repensando la guerra fría: México y Estados Unidos ante el conflicto en Costa Rica en 1948, pretende enmarcar cómo el conflicto civil que se generó en Costa Rica en abril de 1948 debe ser entendido en un contexto internacional enmarcado por las primeras medidas estadounidenses con respecto a su política anticomunista en América Latina. Lo anterior coadyuvará a repensar la postura de la "Guerra Fría temprana", pues fue desde 1948 en que gran parte del continente sintió los embates de este conflicto bipolar, como fue el caso de Costa Rica, Colombia --con el llamado Bogotazo-- y Venezuela a raíz del derrocamiento de Rómulo Gallegos. Con esta idea se reflexiona sobre esa historiografía que considera el caso de Guatemala en 1954 como el primer golpe efectivo a los gobiernos latinoamericanos en el contexto de la Guerra Fría.

Siguiendo la línea ascendente cronológica México como destino final. Desplazamiento territorial y abandono de la militancia revolucionaria en Guatemala, de Juan Carlos Vázquez Medeles, el autor abunda sobre cómo en la década de los años ochenta se caracterizó por el incremento de la violencia instituida a partir de la implementación de la estrategia contrainsurgente de los regímenes militares. El artículo de Vázquez Medeles, analiza la llegada a México de algunos integrantes del Partido Guatemalteco del Trabajo-Partido Comunista, quienes salieron por la represión que contra ellos, ejerció la dictadura militar guatemalteca. Con base en entrevistas que el propio autor realizó a algunos protagonistas del PGT, el autor evidencia el papel que estos luchadores sociales

\section{(c) (i) (9) (2)}

La Revista Estudios es editada por la Universidad de Costa Rica y se distribuye bajo una Licencia Creative Commons Atribución-NoComercial-CompartirIgual 3.0 Costa Rica. Para más información envíe un mensaje a revistaestudios.eeg@ucr.ac.cr. 
Revista Estudios, (38), 2019.

Junio 2019-Noviembre 2019

ISSN 1659-3316

Moreno Rodríguez Laura Beatriz

tuvieron en las actividades disidentes en su país y la manera de relacionarse en México en condiciones de exilio.

Para finalizar Los derechos humanos en El Salvador desde los Acuerdos de Paz de Chapultepec, es el título del trabajo de Liliana Padilla, quien explora los contenidos de los Acuerdos de Paz que sellaron el final del conflicto armado en El Salvador y que al mismo tiempo resignificaron el valor de los Derechos Humanos en el país centroamericano como garante del Estado de derecho, en una nación marcada por la desigualdad, la violencia y la injusticia social que han vertebrado buena parte de su historia como nación soberana desde el siglo XIX. Padilla considera que aún existe un largo camino hacia la conquista del pleno goce de los derechos humanos, que pasa por la atención integral a la violencia y el compromiso del Estado frente a la verdad, la impartición de justicia, la reparación a las víctimas y las garantías de no repetición.

Me resta decir que la integración de estas seis aportaciones académicas son una aproximación a un tema tan actual y coyuntural tanto para México como para los países del istmo, unidos por geografía, lengua, cultura e historia y su lectura son muestra fiel del vínculo inherente que conjunta una vez más a elementos como la diplomacia, la violencia, el exilio, la represión y la cultura; lugares comunes de un lenguaje tan similar que en ocasiones confunde las fronteras territoriales y políticas.

Laura Beatriz Moreno Rodríguez

Imorenor@sre.gob.mx https://orcid.org/0000-0002-3348-5601 Directora General Acervo Histórico Diplomático SRE, México

\footnotetext{
(c) (i) (3) (-)

La Revista Estudios es editada por la Universidad de Costa Rica y se distribuye bajo una Licencia Creative Commons Atribución-NoComercial-Compartirlgual 3.0 Costa Rica. Para más información envíe un mensaje a revistaestudios.eeg@ucr.ac.cr.
} 